\title{
İstanbul'da Bulunan Sağlık Bakanlığı Hastanelerinin Verimlilik Analizi
}

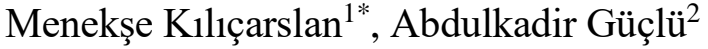 \\ ${ }^{1}$ Istanbul Aydin University, Health Management Department, Istanbul - Turkey, (ORCID: 0000-0002-0580-8645) \\ ${ }^{2}$ Istanbul Aydin University, Health Management Department, Istanbul - Turkey, (ORCID: 0000-0001-8005-5367)
}

(İlk Geliş Tarihi 19 Nisan 2019 ve Kabul Tarihi 30 Mayıs 2019)

(DOI: $10.31590 /$ ejosat.555814)

\begin{abstract}
ATIF/REFERENCE: Kılıçarslan, M. \& Güçlü, A. (2019). İstanbul'da Bulunan Sağlık Bakanlığı Hastanelerinin Verimlilik Analizi. Avrupa Bilim ve Teknoloji Dergisi, (16), 552-558.
\end{abstract}

\begin{abstract}
Öz
Hizmet sektöründe artan rekabet ve buna dayalı maliyetler çok önemli bir yer tutmakta ve rekabet gücünün anahtar rolünü üstlenmektedirler. Hizmet ve hizmetin aksamaması için maliyetlerin azaltılarak gelirin artırılıp hem rekabet gücü hem de hastanelerde hastaların memnuniyeti artacağından Veri zarflama yöntemi önemini giderek artırmaktadır. Bu çalışmada kullanılan Veri Zarflama Analizi (VZA), çok kriterli karar verme yöntemleri arasında son derece yaygın bir kullanım alanı bulmuştur. Her türlü mal ve hizmet üretimi faaliyetleri göz önüne alındığında, artık tek bir girdi kullanarak tek bir çıktı üretimi yapılmadığı görülecektir. Türkiye için önemli bir yer olan İstanbul ilinde faaliyet gösteren kamu hastanelerinin, belirlenen temel girdi ve çıktı göstergeleri ele alınarak etkinlikleri hesaplanmış ve bir etkinlik sıralaması oluşturulmuştur. Ölçüm sonrasında tam etkinlik skoru alamayan karar birimleri için, etkinliklerini artırabilmeleri yönünde önerilerde bulunulmuştur.

Araştırmamıza İstanbul'da bulunan Sağlık Bakanlığı'na bağlı ve girdi ve çıktı verilerine ulaşabildiğimiz 49 hastane dahil edilmiştir. Hastanelerin 2014 yılı yatak, doktor, hemşire ve diğer personel sayıları girdi olarak, poliklinik, acil muayene, yatan hasta, yatılan gün ve ameliyat+doğum sayıları çıktı olarak değerlendirilmiştir. Girdi ve çıktı değerleri Max DEA 7 Basic programı ile ölçeğe göre değişen getiri varsayımına dayalı olan BCC (Banker, Charnes ve Cooper) modeli ile ve çıktıya yönelik veri zarflama analizine tabi tutulmuştur. Yapılan analiz sonucunda 49 hastanenin 24’ü (\% 49) göreli verimli, 25’i (\% 51) göreli verimsiz bulunmuştur. Göreli verimsiz olarak bulunan 25 hastaneden 14'ünün verimlilik skorları 0,90-0,99 arasında, 6 tanesi 0,80-0,89 arasında, kalan 5 tanesi ise 0,15-0,76 arasında bulunmuştur.

Hastane yöneticileri, hastanelerinde performans değerlendirme çalışmaları yaparak mevcut kaynaklarını daha etkin kullanabilirler ve sağlık hizmetleri üretimlerini artırarak toplumun sağlık hizmetleri ihtiyaçlarını daha yüksek oranda karşılayabilirler.
\end{abstract}

Anahtar Kelimeler: Veri Zarflama Analizi, Etkinlik, Hastane, İsraf

\section{Productivity Analysis of Ministry of Health Hospitals in Istanbul}

\begin{abstract}
:
Increasing competition in the service sector and the costs based on this play a key role in the competitive force.To avoid the disruption of service, increasing the revenue by reducing costs will foster competitiveness and satisfaction of patients in hospitals and in this regard, the importance of data envelopment method is highly demanding. In this study, Data Envelopment Analysis (DEA) has found as an extremely widespread use of multi-criteria decision-making methods. Considering the production activities of all kinds of goods and services, it is no longer possible to produce a single output by using a single input.In Turkey, Istanbul is an important province for operating the public hospitals. These hospitals' main input and output indicators were determined and their activities were calculated.
\end{abstract}

1 Sorumlu Yazar: Istanbul Aydin University, Health Management Department, Istanbul - Turkey, ORCID: 0000-0002-0580-8645, meneksevaro169@gmail.com 
By this way, their activity ranking was established.After measurement, suggestions were made to the decision making units who have not got full activity score so as to increase their effectiveness.

In our research, 49 hospitals' which are affiliated to the Ministry of Health in Istanbul, input and output data were included. In 2014, the number of beds, doctors, nurses and other staff of hospitals was used as input data as well as polyclinic, emergency examination, inpatient, days of inpatient, operation + birth numbers were evaluated as output data. Input and output values are scale- varied with Max DEA 7 Basic program and based on the assumption of BCC (Banker, Charnes and Cooper) model as well as output were subjected to data envelopment analysis. As from the result of the analysis, 24 (49\%) of the 49 hospitals were relatively productive and 25 (51\%) were relatively inefficient. Of the 25 hospitals that were found inefficient, 14 hospitals' efficiency scores were between $0.90-0.99,6$ hospitals were between $0.80-0.89$ and the remaining 5 hospitals' were between $0.15-0.76$.Hospital managers can use their existing resources more effectively by ensuring the performance evaluations in their hospitals and increase the productivity of health services. By this way they can meet the health services needs of the community at a higher rate.

Keywords: Data Envelopment Analysis, Activity, Hospital, Waste

\section{Giriş}

Performans kavramı bilimsel literatürde tam anlamı ile bir tanımı bulunmadığınındın çeşitli şekillerde tanımlanmıştır (Gencer, 2006: 6). 16. Yüzyılda, askeri yerlerde görev alanların "başarı ve emirleri yerine getirmeleri şeklinde” kullanılmıştır (Lawson, 1995: 3). Günümüzde ise performans, "belli bir hedefe ulaşmak için yapılan planlar ve amaçlar doğrultusunda varılan nokta" olarak tanımlanmaktadır (Gencer, 2006: 6).

Başka bir deyişle performans, "Bir çalışanın belirli bir zaman kesiti içerisinde kendisine verilen görevi yerine getirmek suretiyle elde ettiği sonuçlardır” (Bingöl, 2003: 273).

Barkey $(2002,26-27)$ ise performansı, örgütlerin, ekonomik avantajlar elde etmek amacı ile bir araya getirilmiş verimli varlıkların bir bileşimi olduğu fikrine dayalı olarak tanımlamaktadır. Bir işletmenin varlıkları, iş görenler, yönetim, girişimcilik yeteneği, fiziksel sermaye gibi unsurlardan oluşur. İşletmeler değer yaratmak için bu varlıkları kullanırlar ve her bir varlık kendisinden beklenen bir değere sahiptir.

Diğer bir anlatımla performans, işletme amaçlarının gerçekleştirilmesi için gösterilen tüm çabaların değerlendirilmesidir (Kenger,2001:38). İşletmelere göre performans “değer yaratabilmek” tir. Performans, hem “doğru işin yapılması" (strateji) hem de "işin doğru yapılması" (Toplam Kalite Yönetimi) ile sağlanabilmektedir. İşletmecilik açısından fonksiyonelliğin kalitesi olarak anlaşılan performans, yönetim açısında ise, yönetim kalitesi ile ilişkilendirilmektedir. 21. Yüzyılın başlarında Taylor'un gerçekleştirdiği üretkenlik ölçümleri ile başlayan performans ölçümü ve değerlendirilmesine yönelik ilgi günümüze kadar sürekli bir artış eğilimi göstererek devam etmektedir (Pervaiz vd., 1999: 305). Performans kavramının bu değişim süreci içerisinde değişmeyen ve önemini yitirmeyen tek boyut ekonomikliktir. İster özel, ister kamu, ister üretime yönelik, isterse hizmet kurumları olsun kârlılık ve dolayısı ile ekonomiklik temelinde varlıklarını sürdürmek yarışı içindedirler. Kâr ve kârlılık, hem işletme hem de toplum için önem arz etmektedir(Gencer, 2006: 7). İşletme performansı geniş bir boyut içerisinde aşağıdaki sorulara yanıt arayan bir kavram olarak ortaya çıkmaktadır (Gencer, 2006: 8).

- Şimdi neredeyiz?

- Daha ne kadar iyi olabilirdik?

- Nerede olmaliyız?

$\mathrm{Bu}$ üç temel soru işletme performansının ne anlama geldiğini genel olarak açıklamaktadır. Yine bu üç temel soru işletme performansının tanımlanması ve değerlendirilmesine ilişkin alanları belirlemektedir. Son dönemlerdeki sınıflandırmada, örgütsel bir sistemde performans kavramı aşağıdaki boyutlar ile tanımlanmaktadır. Bunlar (Kenger, 2001: 39-43);

Etkenlik (effectiveness), Verimlilik (productivity), Etkililik (efficiency, İktisadilik (economic), Kalite (quality), Çalışma yaşamının kalitesi (quality of working life), Kârlılık ve bütçeye uygunluk (rantabilite, profitability, budgetability), Yenilik (innovation).

Sağlıkta performans ve etkileri genel anlamda değerlendirilirse en önemli etkisi işletmelerin maliyetlerinin azalması ile birlikte verimliliğin artması olarak görülmektedir.

\section{Genel Bilgiler}

\section{A. Veri Zarflama Analizi}

Tüm organizasyonlarda etkinlik değerlendirmesi ile mevcut olan durumun ortaya konulmasında amaçtan çok hedeflerin ölçülebilmesi, gerçekleşme potansiyellerinin belirlenmesi ve mümkün olabildiğince iyileşme potansiyeline sahip olan alanların belirlenebilmesi için önemli bir araç haline gelmektedir.

Organizasyonların varlık amaçlarını çok iyi bir şekilde belirlemesi, hedefler doğrultusunda sürekli ölçüm yapabilmesi, yönetimin en önemli faaliyet alanları içinde olmalıdır. (Demirci, 2012:13). Günümüz koşullarında üretim alanında çalışan organizasyonların sıklıkla başvurduğu etkinlik ölçüm yöntemi Veri Zarflama Analizi (VZA)'dir.

VZA’yı diğer yöntemlerden ayıran bazı temel özellikler ise aşağıda gösterilmektedir (Chu vd., 2008:19);

- Maksimum üretim hesaplamalarında kullanılan yöntem, sonuç fonksiyonu ile başlangıçta olan girdi ve çıktılar arasında bir ilişki kurabilmenin mümkün olamaması nedeniyle, yanlış bir fonksiyon oluşturma riskinden uzaklaşmış olunur.

- VZA, değişik ölçü birimlerinden uzak, matematiksel tabanlı bir yöntemdir.

- VZA ile daha objektif ve tarafsız sonuçlar elde edilir.

VZA hesaplamaları aşağıda belirtilen özelliklerden dolayı diğerlerinden daha çok ön plana çıkmaktadır. (Charnes vd, 1997:7-8);

- Ana kütle değerlerine değil, kişisel gözleme dayanır, 
Avrupa Bilim ve Teknoloji Dergisi

- Farklı ölçü birimleri, çoklu girdi ve çoklu çıktı verileri aynı formülde hesaplanabilir,

- Dış kaynaklı değişkenlere uyum sağlanabilir,

- Parametrelere bağlı değildir, başlangıçta fiyat veya ağırlık bilgileri gerektirmez,

- Üretim ilişkilerinin herhangi bir fonksiyonunda sınırlama yoktur.

Çoklu girdi ve çoklu çıktı kullanılarak analiz yapılabilen VZA, önceden belirlenmiş herhangi bir fonksiyonel ilişkiye bağlı olmadan, her bir karar biriminin etkinsizliğini miktar ve kaynağı ile belirleme yeteneğine sahiptir (Bakırc1, 2006:167).

\section{B. Veri Zarflama Analizi Modelleri}

VZA analizinin tarihi; 1957'de ve 1978'de Journal of Operations Research'de yayınlanan makaleden esinlenerek yapılan Edwordo Rhodes'un Cornegie Mellon Üniversitesi'ndeki “Şehir ve Kamu” doktora tezi ile ortaya çıkmıştır. Dikkat izleme testlerine katılan ve katılmayan okulların etkinliklerinin karşılaştırılması sonucunda ortaya çıkan VZA günümüzde özel ve kamu sektöründe oldukça yaygın olarak kullanılmaktadır.

VZA modellerinden biri Charnes, Cooper, Rhodes tarafindan araştırılıp bulunan ve isimlerin baş harfiyle oluşan CCR modeli, ölçeğe göre sabit getiri varsayımı ile toplam etkinliği ölçmektedir.

Diğer bir VZA modeli olan Banker, Charnes, Cooper'ın çalışmaları ile ortaya konulan ve geliştirilen BBC modeli ise ölçeğe göre sabit değil değişken getiri ile benzer ölçekteki birimleri birbirleri ile karşılaştırarak sadece teknik etkinliği ölçmeye yaramaktadır.

\section{Veri Zarflama Analizinin Kullanım Amaçları}

Etkili bir performans değerlendirme sisteminin sonucunda bulunan bilgiler, yönetim için karar almada en değerli olan bilgilerdir. VZA'nın uygulama amaçları ise aşağıdaki gibi sıralanabilir (Altun, 2006:22);

- Karşılaştırılan girdi- çıktı boyutlarından elde edilen değerler ile birimdeki etkin olmayan kaynağın ve miktarının belirlenmesi,

- Karşılaştırılan birimlerin etkinliklerinin sınıflandırılabilmesi,

- Karşılaştırılan birimlerin yönetim şekillerinin değerlendirilebilmesi,

- Özel olan girdi-çıktı ilişkileri için yürürlükteki standartların gerçekleşen performansa göre incelenmesi ve gözden geçirilmesi ile önceki çalışmalar ile sonuçların karşılaştırılabilmesi

\section{Veri Zarflama Analizinin Uygulama Așamaları}

VZA ile etkinlik değerlendirmesinde üç aşama bulunmaktadır (Golany ve Roll, 1989:136);

- Analize tabi olacak karar birimlerinin tanımlanması ve seçilmesi,

- Seçilmiş olan karar birimlerinin göreceli olarak etkinliklerinin değerlendirilmesi için gerekli olan girdi ve çıktı faktörlerinin belirlenmesi,

- VZA modellerinin uygulanabilmesi ve sonuçların analiz edilmesi.

Karar birimlerinin seçilmesinde, iki çok önemli faktör bulunmaktadır. Bu önemli iki faktör; homojenlik ve karar birimi sayısıdır. Bu bilgiler 1şı̆̆ında (Ramanathan, 2003:173);

- Karar birimleri homojen olmalıdır,

- Karşılaştırılacak karar birimleri ile kıyaslanacak homojen birimlerinin sayısı uygulanacak VZA yönteminin amacına bağglı olarak değişmektedir.

Veriler arasında eksik, hatalı veya aşırı uç noktada olanlar, analiz sonucunda elde edilecek etkinlik puanını etkileyeceği için, bu tür veriler tespit edilip araştırma dışına çıkarılmalıdır. (Özata, 2004:101). Etkinlik hesaplamaları sonucunda her bir karar biriminin 0 ile 1 arasında etkinlik değeri elde edilir. 1'e eşit olan etkinlik değeri en iyi gözlem kümesini oluşturur. Etkinlik değeri eğer 1'den küçük ise karar birimleri göreceli olarak etkin kabul edilmezler. VZA'nın son aşamasında ise gözlem kümelerinde etkin olan ve olmayan karar birimleri için ortak olan sonuçlar elde edilmeye çalışılır. VZA modelinin etkin olabilmesi için girdi ve çıktı sayılarının çok sayıda olması istenir. (Demirtaş, 2005: 15).

\section{E. Veri Zarflama Analizinin Güçlü Yönleri}

- VZA, ekonomik teori ile desteklenmekte ve mutlak olarak değil göreceli etkinlik üzerine odaklanarak, çoklu girdi ve çıktıları formüle edebilme özelliği ile yaygın olarak kullanımına imkân sağlamıştır (Kontodimopoulos vd, 2007:39),

- VZA, ana kütlenin ortalamasını almak yerine, en iyi olana göre performans değerlendirmesi yapar. Verilen her bir karar birimi için en iyi örnek ve sınır tanımlanır. Bu sınırlar doğrultusunda etkin veya etkin olmayan kararı verilir (Mok vd, 2007:74),

- Etkinlik ölçümünde kullanılan tekniklerin en önemli avantajlarından biri de az sayıda gözlem kümesi ile sonuca ulaşabilme özelliğidir (Pasiouras vd, 2008:12),

\section{F. Veri Zarflama Analizinin Zayıf Yönleri}

- Etkinlik skoru 1 olarak belirlenen bir karar biriminde etkinliğin mükemmel seviyede olduğu belirlenerek daha fazla arttırılamayacağı gibi algılar, performans artışındaki engellerden biri olarak karşımıza çıkabilir,

- Parametrik değerler kullanılmadığı için istatistiksel olarak gözlem farklarının açıklanabilmesi mümkün değildir (Pereira, 2006:90),

- VZA yöntemi modelleme hatalarına ve ölçüm hatalarına karşı hassastır (Hansson, 2007:4),

- VZA sadece ele alınan grup içerisinde bir sonuç sağlar. Grup dışında kalanların etkin bir karar birimi olabilme olasılığı göz ardı edilmektedir,

- Kalitatif girdi ve çıktı ölçüleri, elde edilen bulguları zayıflatabilmektedir,

- Ciddi öneme sahip girdi ve çıktıların küme dışı kalmaları sonucu, elde edilen bulgular yanıltıcı olabilmektedir,

- VZA, statik ve tek zaman kesitinde değerlendirilen modellerdir. Gerçek zamanla kıyaslama yapıldığında bazı karar birimlerinin etkinliği için süre gereklidir. Üretim süreci dinamik bir yapıdadır. 


\section{Gereç ve Yöntem}

Araştırmamıza İstanbul'da bulunan Sağlık Bakanlığı'na bağlı ve girdi ve çıktı verilerine ulaşabildiğimiz 49 hastane dahil edilmiştir. Araştırmamızda yararlandığımız veriler Türkiye Kamu Hastaneleri Kurumu tarafından 2015 yılında yayınlanan 2014 yılı Kamu Hastaneleri İstatistik Yıllığından elde edilmiştir. Hastanelerin 2014 yılı yatak, doktor, hemşire ve diğer personel sayıları girdi olarak, poliklinik, acil muayene, yatan hasta, yatılan gün ve ameliyat+doğum sayıları çıktı olarak değerlendirilmiştir. Girdi ve çıktı değerleri Max DEA 7 Basic programı ile ölçeğe göre değişen getiri varsayımına dayalı olan BCC (Banker, Charnes ve Cooper) modeli ile ve çıktıya yönelik veri zarflama analizine tabi tutulmuştur.

\section{Bulgular}

Araştırma kapsamına alınan 49 hastanenin 24’ü (\% 49) verimli, 25’i (\% 51) göreli verimsiz bulunmuştur. Göreli verimsiz bulunan hastanelerin verimlilik skorları 0,15 ile 0,99 arasında değişmektedir. Bu hastanelerin 14 tanesinin verimlilik skorları 0,90 ile 0,99 arasında, 6 hastanenin verimlilik skorları 0,80-0,89 arasında ve 5 hastanenin ise 0,15-,076 arasında bulunmuştur. Hastanelerin 2014 yılı girdi ve çıktı değerleri ile yapılan verimlilik ölçümleri sonucu bulunan değerler tablo-1'de sunulmuştur.

Göreli verimli bulunan hastanelerin tüm girdilerini ve tüm çıktılarını verimli kullandıkları değerlendirilmektedir. Bu nedenle göreli verimli bulunan hastanelerle ilgili herhangi bir ileri değerlendirme yapılmaya gerek duyulmamaktadır.

Göreli verimsiz bulunan hastanelerin hangi girdilerini gereksiz kullandıkları veya bu girdilerini verimsiz kullanmaları nedeniyle hangi çıktı miktarını ne kadar oranda az ürettikleri ile ilgili değerlendirmeler yapılabilir.

Tablo-1 Hastanelerin 2014 yılı verimlilik skorları

\begin{tabular}{|c|c|c|c|}
\hline HASTANE ADI & $\begin{array}{l}\text { VERİMLILIK } \\
\text { SKORU }\end{array}$ & HASTANE ADI & $\begin{array}{l}\text { VERIMLILIK } \\
\text { SKORU }\end{array}$ \\
\hline KARTAL LÜTFİ KIRDAR EA.HST. & 1,00 & $\begin{array}{l}\text { GAZIOSMANPAŞA TAKSİM EA } \\
\text { HASTANESI }\end{array}$ & 0,99 \\
\hline HAYDARPAŞA NUMUNE EA HST. & 1,00 & FİZIK TEDAVİ VE REH. EA HASTANESİ & 0,99 \\
\hline $\begin{array}{l}\text { İ.MEDENIYET ÜNIV. GÖZTEPE EA } \\
\text { HST. }\end{array}$ & 1,00 & DR.SADİ KONUK EA HST. & 0,97 \\
\hline BAĞCILAR EA HASTANESİ & 1,00 & ARNAVUTKÖY DEVLET HASTANESİ & 0,97 \\
\hline KANUNİ SULTAN SÜLEYMEN EA HST. & 1,00 & EYÜP DEVLET HASTANESİ & 0,97 \\
\hline HASEKİ EA HASTANESİ & 1,00 & BEYKOZ DEVLET HASTANESİ & 0,97 \\
\hline $\begin{array}{l}\text { Z. KAMİL KADIN VE ÇOCUK HST. EA } \\
\text { HST. }\end{array}$ & 1,00 & ÜMRANIYE EA HASTANESİ & 0,96 \\
\hline M. OSMAN RUH SAĞ. HAST. EA HAST & 1,00 & FATIH SULTAN MEHMET EA HST. & 0,94 \\
\hline $\begin{array}{l}\text { REŞAT BELGER BEYOĞLU GÖZ EA } \\
\text { HST. }\end{array}$ & 1,00 & M. SABANCI KEMIK HAST. EA HST & 0,94 \\
\hline $\begin{array}{l}\text { YAKACIK DOĞ. VE ÇOCUK HAST. } \\
\text { HST. }\end{array}$ & 1,00 & ERENKÖY RUH VE SINIIR HST. EA HST. & 0,93 \\
\hline MESLEK HASTALIKLARI HASTANESİ & 1,00 & ÜSKÜDAR DEVLET HASTANESİ & 0,91 \\
\hline ERENKÖY FTR HASTANESI & 1,00 & MARMARA ÜN. PENDİK EA HST. & 0,91 \\
\hline LEPRA DERİ VE ZÜHREVİ HAST. HST. & 1,00 & İSTINYE DEVLET HASTANESI & 0,91 \\
\hline $\begin{array}{l}\text { İSTANBUL PENDİK DEVLET } \\
\text { HASTANESİ }\end{array}$ & 1,00 & $\begin{array}{l}\text { YEDİKULE GÖĞ HAST. VE CERR. EA } \\
\text { HST. }\end{array}$ & 0,90 \\
\hline TACİRLER EĞT. VAKFI DEVLET HST. & 1,00 & SİLIVRİ DEVLET HASTANESİ & 0,89 \\
\hline KAĞITHANE DEVLET HASTANESİ & 1,00 & İSTANBUL EA HASTANESİ & 0,87 \\
\hline ESENYURT DEVLET HASTANESI & 1,00 & KOŞUYOLU YÜKSEK İHTISAS EA HST. & 0,86 \\
\hline BAŞAKŞEHIIR DEVLET HASTANESİ & 1,00 & MALTEPE DEVLET HASTANESİ & 0,85 \\
\hline BAYRAMPAŞA DEVLET HASTANESİ & 1,00 & İLYAS ÇOKAY DEVLET HASTANESİ & 0,80 \\
\hline SAİT ÇİFTÇİ DEVLET HASTANESİ & 1,00 & DR.SIYYAMİ ERSEK GKDC EA HST. & 0,80 \\
\hline İSMAİL AKGÜN DEVLET HASTANESİ & 1,00 & $\begin{array}{l}\text { M.AKİF ERSOY GKD CERRAHİSI EA } \\
\text { HST. }\end{array}$ & 0,76 \\
\hline $\begin{array}{l}\text { SİLIVRİ CEZA İNFAZ KURUMU } \\
\text { DEV.HST. }\end{array}$ & 1,00 & MURAT KÖLÜK DEVLET HASTANESİ & 0,62 \\
\hline $\begin{array}{l}\text { LÜTFIYYE NURİ BURAT DEVLET } \\
\text { HASTANESİ }\end{array}$ & 1,00 & $\begin{array}{l}\text { SÜREYYAPAŞA GÖĞ.HST.VE CERR.EA. } \\
\text { HST. }\end{array}$ & 0,56 \\
\hline \multirow[t]{2}{*}{ ŞİLE DEVLET HASTANESİ } & 1,00 & BAHÇELİEVLER DEVLET HASTANESİ & 0,29 \\
\hline & & $\begin{array}{l}\text { ESENLER KAD. DOĞ. VE ÇOCUK HAST. } \\
\text { HST. }\end{array}$ & 0,15 \\
\hline
\end{tabular}


Bu kapsamda; tablo-2'de bulunan 9 hastane mevcut 2905 yatağının 391 tanesini kullanmayarak aynı miktarda çıktı üretebilirdi. Bir başka deyişle bu hastanelerdeki 391 yatak için yapılan tüm giderler gereksiz yapılmıştır. Bu hastaneler 2905 açık yatak bulundurmak yerine 2514 yatak ile de aynı miktarda hastaya hizmet verebilirlerdi.

Tablo-2 Yatak Girdilerini Verimsiz Kullanan Hastaneler

\begin{tabular}{|l|c|c|c|c|}
\hline Hastane Adı & $\begin{array}{c}\text { Verimlilik } \\
\text { Skoru }\end{array}$ & Yatak Sayısı & $\begin{array}{c}\text { Fazla Girdi } \\
\text { Miktarı }\end{array}$ & $\begin{array}{c}\text { Optimum Girdi } \\
\text { Miktarı }\end{array}$ \\
\hline DR.SADİ KONUK EA HST. & 0,97 & 612 & -82 & 530 \\
\hline ARNAVUTKÖY DEVLET HASTANESİ & 0,97 & 201 & -24 & 177 \\
\hline FATİH SULTAN MEHMET EA HST. & 0,94 & 300 & -6 & 294 \\
\hline ÜSKÜDAR DEVLET HASTANESİ & 0,91 & 263 & -88 & 175 \\
\hline İSTİNYE DEVLET HASTANESİ & 0,91 & 128 & -10 & 118 \\
\hline SİLIVRİ DEVLET HASTANESİ & 0,89 & 223 & -29 & 194 \\
\hline DR.SIYYMİ ERSEK GKDC EA HST. & 0,80 & 525 & -64 & 461 \\
\hline $\begin{array}{l}\text { SÜREYYAPAS̆A GÖĞ̈S HST.VE } \\
\text { GÖG.CERR.EA.HST. }\end{array}$ & 0,56 & 503 & -15 & 488 \\
\hline ESENLER KADIN DOĞ. VE ÇOCUK HST. HAST. & 0,15 & 150 & -73 & 77 \\
\hline \multicolumn{1}{|c|}{ TOPLAM } & & 2.905 & -391 & 2514 \\
\hline
\end{tabular}

Tablo-3'de bulunan 16 hastane mevcut 2724 doktorun 644 tanesini kullanmayarak aynı miktarda çıktı üretebilirdi. Bir başka deyişle bu hastanelerdeki 644 doktor gereksiz istihdam edilmiştir. Bu hastaneler 2724 doktor bulundurmak yerine 2080 doktor ile de aynı miktarda hastaya hizmet verebilirlerdi.

Tablo-3 Doktor Girdilerini Verimsiz Kullanan Hastaneler

\begin{tabular}{|c|c|c|c|c|}
\hline Hastane Adı & $\begin{array}{l}\text { Verimlilik } \\
\text { Skoru }\end{array}$ & $\begin{array}{l}\text { Doktor } \\
\text { Sayısı }\end{array}$ & $\begin{array}{l}\text { Fazla Girdi } \\
\text { Miktarı }\end{array}$ & $\begin{array}{l}\text { Optimum Girdi } \\
\text { Miktarı }\end{array}$ \\
\hline GAZİOSMANPAŞA TAKSIM EA HASTANESİ & 0,99 & 187 & -31 & 156 \\
\hline DR.SADİ KONUK EA HST. & 0,97 & 321 & -79 & 242 \\
\hline ARNAVUTKÖY DEVLET HASTANESİ & 0,97 & 87 & -3 & 84 \\
\hline EYÜP DEVLET HASTANESİ & 0,97 & 90 & -13 & 77 \\
\hline BEYKOZ DEVLET HASTANESİ & 0,97 & 149 & -43 & 106 \\
\hline ÜMRANIYYE EA HASTANESİ & 0,96 & 230 & -63 & 167 \\
\hline FATİH SULTAN MEHMET EA HST. & 0,94 & 202 & -59 & 143 \\
\hline M. SABANCI KEMIKK HST. EA HAST. & 0,94 & 89 & -15 & 74 \\
\hline ÜSKÜDAR DEVLET HASTANESİ & 0,91 & 138 & -55 & 83 \\
\hline MARMARA ÜN. PENDİK EA HST. & 0,91 & 324 & -79 & 245 \\
\hline İSTINYE DEVLET HASTANESİ & 0,91 & 83 & -29 & 54 \\
\hline $\begin{array}{l}\text { YEDİKULE GÖĞÜS HST. VE GÖĞ.CERR. EA } \\
\text { HAST. }\end{array}$ & 0,90 & 109 & -11 & 98 \\
\hline İSTANBUL EA HASTANESİ & 0,87 & 281 & -59 & 222 \\
\hline DR.SIYYAMİ ERSEK GKDC EA HST. & 0,80 & 183 & -66 & 117 \\
\hline $\begin{array}{l}\text { MEHMET AKİF ERSOY GKD CERRAHİSİ EA } \\
\text { HAST. }\end{array}$ & 0,76 & 127 & -16 & 111 \\
\hline $\begin{array}{l}\text { SÜREYYAPAŞA GÖĞÜS HST.VE } \\
\text { CERR.EA.HST. }\end{array}$ & 0,56 & 124 & -23 & 101 \\
\hline TOPLAM & & 2724 & -644 & 2.080 \\
\hline
\end{tabular}

Tablo-4'de bulunan 18 hastane mevcut 4.786 hemşirenin 1.338 tanesini kullanmayarak da aynı miktarda çıktı üretebilirdi. Bir başka deyişle bu hastanelerdeki 1.338 hemşire gereksiz istihdam edilmiştir. Bu hastaneler 4.786 hemşire bulundurmak yerine 3.448 hemşire ile de aynı miktarda hastaya hizmet verebilirlerdi. 
Tablo-4 Hemşire Girdilerini Verimsiz Kullanan Hastaneler

\begin{tabular}{|c|c|c|c|c|}
\hline Hastane Adı & $\begin{array}{l}\text { Verimlilik } \\
\text { Skoru }\end{array}$ & $\begin{array}{l}\text { Hemşire } \\
\text { Sayısı }\end{array}$ & $\begin{array}{l}\text { Fazla Girdi } \\
\text { Miktarı }\end{array}$ & $\begin{array}{l}\text { Optimum Girdi } \\
\text { Miktarı }\end{array}$ \\
\hline GAZIOSMANPAŞA TAKSIM EA HASTANESİ & 0,99 & 402 & -70 & 332 \\
\hline FİİK TEDAVİ VE REH. EA HASTANESİ & 0,99 & 103 & -27 & 76 \\
\hline BEYKOZ DEVLET HASTANESİ & 0,97 & 229 & -36 & 193 \\
\hline ÜMRANIYYE EA HASTANESİ & 0,96 & 597 & -99 & 498 \\
\hline FATİH SULTAN MEHMET EA HST. & 0,94 & 288 & -33 & 255 \\
\hline ERENKÖY RUH VE SINIIR HST. EA HST. & 0,93 & 132 & -50 & 82 \\
\hline ÜSKÜDAR DEVLET HASTANESİ & 0,91 & 201 & -73 & 128 \\
\hline İSTINYE DEVLET HASTANESİ & 0,91 & 94 & -12 & 82 \\
\hline $\begin{array}{l}\text { YEDİKULE GÖĞÜS HST. VE GÖĞ.CERR. EA } \\
\text { HAST. }\end{array}$ & 0,90 & 212 & -41 & 171 \\
\hline SİLIVRİ DEVLET HASTANESİ & 0,89 & 174 & -23 & 151 \\
\hline İSTANBUL EA HASTANESİ & 0,87 & 513 & -15 & 498 \\
\hline $\begin{array}{l}\text { KARTAL KOŞUYOLU YÜKSEK İHTISAS EA } \\
\text { HST. }\end{array}$ & 0,86 & 427 & -179 & 248 \\
\hline MALTEPE DEVLET HASTANESİ & 0,85 & 42 & -5 & 37 \\
\hline ÇATALCA İLYAS ÇOKAY DEVLET HASTANESİ & 0,80 & 83 & -42 & 41 \\
\hline DR.SIYYAMİ ERSEK GKDC EA HST. & 0,80 & 429 & -214 & 215 \\
\hline $\begin{array}{l}\text { MEHMET AKİF ERSOY GKD CERRAHİSİ EA } \\
\text { HAST. }\end{array}$ & 0,76 & 485 & -306 & 179 \\
\hline $\begin{array}{l}\text { SÜREYYAPAŞA GÖĞÜS HST.VE } \\
\text { GÖĞ.CERR.EA.HST. }\end{array}$ & 0,56 & 295 & -97 & 198 \\
\hline ESENLER KADIN DOĞ. VE ÇOCUK HST. HAST. & 0,15 & 80 & -16 & 64 \\
\hline TOPLAM & & 4.786 & -1.338 & 3.448 \\
\hline
\end{tabular}

Tablo-5'de bulunan 11 hastane mevcut 9.350 diğer personelin 1.720 tanesini kullanmayarak da aynı miktarda çıktı üretebilirdi. Bu hastanelerdeki 1.720 diğer personel gereksiz istihdam edilmiştir. Tablo-5'de bilgileri verilen hastaneler 9.350 diğer personel bulundurmak yerine 7.630 personel ile de aynı miktarda hastaya hizmet verebilirlerdi.

Tablo-5 Diğer Personel Girdilerini Verimsiz Kullanan Hastaneler

\begin{tabular}{|c|c|c|c|c|}
\hline Hastane Adı & $\begin{array}{l}\text { Verimlilik } \\
\text { Skoru }\end{array}$ & $\begin{array}{l}\text { Diğer Per. } \\
\text { Sayısı }\end{array}$ & $\begin{array}{l}\text { Fazla Girdi } \\
\text { Miktarı }\end{array}$ & $\begin{array}{l}\text { Optimum } \\
\text { Girdi Miktarı }\end{array}$ \\
\hline GAZIOSMANPAŞA TAKSIM EA HASTANESİ & 0,99 & 1.297 & -254 & 1.043 \\
\hline FİZIK TEDAVİ VE REH. EA HASTANESİ & 0,99 & 319 & -59 & 260 \\
\hline DR.SADİ KONUK EA HST. & 0,97 & 1.717 & -22 & 1.695 \\
\hline ÜMRANIYYE EA HASTANESİ & 0,96 & 1.744 & -481 & 1.263 \\
\hline $\begin{array}{l}\text { BALTALİMANI METİN SABANCI KEMİK HST. EA } \\
\text { HAST. }\end{array}$ & 0,94 & 410 & -13 & 397 \\
\hline ERENKÖY RUH VE SINIIR HST. EA HST. & 0,93 & 364 & -83 & 281 \\
\hline MARMARA ÜN. PENDİK EA HST. & 0,91 & 2.188 & -635 & 1.553 \\
\hline ÇATALCA İLYAS ÇOKAY DEVLET HASTANESİ & 0,80 & 211 & -57 & 154 \\
\hline AVCILAR MURAT KÖLÜK DEVLET HASTANESİ & 0,62 & 341 & -27 & 314 \\
\hline BAHÇELIEEVLER DEVLET HASTANESİ & 0,29 & 481 & -22 & 459 \\
\hline ESENLER KADIN DOĞ. VE ÇOCUK HST. HAST. & 0,15 & 278 & -67 & 211 \\
\hline TOPLAM & & 9.350 & -1.720 & 7.630 \\
\hline
\end{tabular}




\section{Sonuç}

Sonuç olarak, göreli verimsiz bulunan hastanelerin toplamda 391 yatak, 644 doktor, 1338 hemşire ve 1720 diğer personel girdisini gereksiz kullandıkları görülmektedir.

Göreli verimsiz bulunan hastanelerin kaynaklarını verimsiz kullanmaları nedeniyle hangi çıktılarını ne oranda eksik ürettikleri incelendiğinde, hastanelerin mevcut kaynaklarıyla 1.006 .420 poliklinik muayenesi, 1.494 .270 acil poliklinik muayenesi, 60.862 hastayı yatırarak tedavi hizmeti ve 49.166 gün hasta yatırma, 122.694 ameliyat ve doğum gerçekleştirme kapasitelerini kullanmamışlardır.

Hastane yönetimlerinin yeterli yönetsel becerilere sahip olmaması, hastanelerde mevcut kaynakların (yatak ve personel) etkin kullanılmayarak, hizmet ihtiyacı olan hastaların sağlık hizmetlerine ulaşımı problemlerine (hizmet alamama, sıra bekleme gibi) neden olmaktadir.

Sağlık ve hastane yöneticileri, hastanelerinde iş etüdü, kadro analizi, insan gücü planlaması gibi personel performans değerlendirme çalışmaları yaparak ve ayrıca etkin bir randevu, yatak ve ameliyathane planlaması ile mevcut kaynaklarını daha etkin kullanabilirler ve sağlık hizmetleri üretimlerini artırarak toplumun sağlık hizmetleri ihtiyaçlarını daha yüksek oranda karşılayabilirler.

\section{Kaynaklar}

Altun, D. (2006), Türk Telekomünikasyon A.Ş. İ Telekom Müdürlüklerinin Veri Zarflama Analizi İle Etkinlik Ölçümü, (Yayınlanmamış Yüksek Lisans Tezi), GaziÜniversitesi Fen Bilimleri Enstitüsü, Ankara

Bakırcı, F., (2006), Üretimde Etkinlik ve Verimlilik Ölçümü, Veri Zarflama Analizi, Teori ve Uygulama, Atlas Yayınları, İstanbul.

Bakırcı, F., (2007), "Firma Etkinliğini Etkileyen Faktörler: Türk Tekstil Sektöründe Bir VZA ve Tobit Model Uygulaması", EKEV Akademi Dergisi, 11 (30).

Bakırcı, M., (2012), "Ulaşım coğrafyası açısından Türkiye'de havayolu ulaşımının tarihsel gelişimi ve mevcut yapısı”, Marmara Coğrafya Dergisi, Say1: 25, İstanbul.

Charnes, A., Cooper, W,W., Lewin, A.Y., Seiford, L.M., (1997), Data Envelopment Analysis: Theory, Methodology and Application, Kluwer Academic Publishers, USA.127

Chu, M.T., Shyu, J.Z., Khosia, R., (2008), "Mesuring The Relative Performance For Leading Fabbles Firms by Using Data Envelopment Analysis”, [Önemli Firmaların Göreceli Performanslarının Veri Zarflama Analizi Kullanarak Ölçümü], Journal of Intelligent Manufacturing

Golany, B. Roll, Y., (1989), “An Aplication Procedure For DEA”, [VZA İçin Bir Uygulama Prosedürü], International Journal of Management Science, 17 (3).

Hansson, H.(2007), “The Links Between Management's Critical Success Factors and Farm Level Economic Performance on Dairy Farms in Sweden”, [İsveç’teki Süt Endüstrisinde Yönetimin Kritik Başarı Faktörleriyle Tarıma Dayalı Ekonomik Performans Arasındaki İlişki], Food Economics, Acta Agriculturae Scandinavica Section C, 4.

Demirci, A, (2012), OECD Üyesi Ülkelerin Ekonomik Ve Sosyal Etkinliklerinin Veri Zarflama Analizi Yöntemiyle Belirlenmesi, Atatürk Üniversitesi Sosyal Bilimler Enstitüsü İşletme Anabilim Dalı, (Yayınlanmamış Doktora Tezi), Erzurum

Kontodimopoulos, N., Moschovakis G., Aletras V., Niakas D., (2007), “The Effect of Environmental Factors on Technical and Scale Efficiency of Primary Health Care Providers in Greece”, [Çevresel Koşulların Yunanistan'daki Temel Sağlık Sektörünün Teknik ve Ölçek Etkinlikleri Üzerindeki Etkinleri], Cost Effectiveness and Resource Allocation, BioMed Central Publishes.

Kula, V., Özdemir L, (2007), “Çimento Sektöründe Göreceli Etkinsizlik Alanlarının Veri Zarflama Analizi Yöntemi İle Tespiti”, Afyon Kocatepe Üniversitesi İ.̇.B.F. Dergisi, IX (1).

Demirtaş, S., (2005), Veri Zarflama Analizi İle Kişisel Bilgisayar Donanımlarının Performans Ölçümün, (Yayınlanmamış Yüksek Lisans Tezi), Çukurova Üniversitesi Sosyal Bilimler Enstitüsü İşletme Anabilim Dalı, Adana.

Mok, V., Yeung G., Han Z., Li Z., (2007), "Leverage, Technical Efficiency and Profitability: An Application of DEA to ForeignInvested Toy Manufactoring Firms in China", [Zorlama, Teknik Etkinlik ve Karlılık: Yabancı Yatırımlı ÇinOyuncak Endüstrisinde VZA Uygulamas1], Journal of Contemporary China, 16 (51).

Özata, M., (2004), Sağlık Bilişim Sistemlerinin Hastane Etkinliğinin Artırılmasında Yeri ve Önemi (Veri Zarflama Analizine Dair Bir Uygulama), (Yayınlanmamış Doktora Tezi), Selçuk Üniversitesi Sosyal Bilimler Enstitüsü İşletme Anabilim Dalı, Konya.

Pereira, A., (2006), Economies of Scale in Blood Banking: A Study Based on Data Envelopment Analysis, Vox Sanguinis, 90.

Pasiouras, F., Liadaki A., Zopounidis C., (2008), "Bank Efficiency and Share Performance: Evidence From Greece”, [Banka Etkinliği ve Hisse Senedi Performans1: Yunanistan Örneği], Applied Financial Economics, 18.

Barkey J. B., (2002). Gaining and sustaining Competitive Advantage. New Jersey: Prentice Hall, p.26-27.

Bingöl D., ( 2003). İnsan Kaynakları Yönetimi, Beta Yayınları, 5. Bası, İstanbul, s.273.

Gencer H., (2006). "Genel İşletme Performansı ve Finansal Performans İlişkisi - Çimento Sektöründe Bir Uygulama”, Yayınlanmamış Yüksek Lisans Tezi, Gaziantep Üniversitesi Sosyal Bilimler Enstitüsü, Gaziantep.

Kenger, E., (2001). Denetçi Yardımcıları Eğitim Notu, s.38-43.(http:// www.ydk.gov.tr/egitim notlari/denetim.htm)

Pervaiz K.A., Kwang K.L., Mohammed Z., (1999). "Measurement Practice for Knowledge Manegement. Journal of Workplace Learning: Employee Courselling Today”, Volume II, Number 8, MCB University Pres, s.305-307. 